\title{
Study on Information-led System Operation of Public Order Maintenance
}

\author{
Dong Cai ${ }^{1, a}$, Wei Wei ${ }^{2, b}$ \\ ${ }^{1}$ Public Security Management Department, Jiangsu Police Institute, Nanjing, P.R.China \\ ${ }^{2}$ Information and Communications Branch, State Grid Electric Power Research Institute, Nanjing, \\ P.R.China
}

ajickie_cd@126.com, bweiwei@163.com

Keywords: information-led policing; system of public order maintenance; operation

\begin{abstract}
In the background of economic globalization and social information, the typical characteristics of information-led social security prevention and control system includes the information dominant, work integrity, scientific decision-making, dynamic service, quick and accurate action etc. The information-led social security prevention and control system is made up of five system, which includes information warning system, decision system, prevention and control system, performance appraisal system, and police guarantee system. These five systems also contain sub systems. Through the leading role of information and its sustainable effect, the system can run fast, integrated, and accurate, so as to realize the social security prevention and control work comprehensive, coordinated, sustainable.
\end{abstract}

\section{Introduction}

During the time of economic globalization rapid development, and network rapid expansion, the Chinese is in a special historical period of social transition. In this background, social security situation in our country is very complex, which has an deeply impact on national security and social stability. There's more no telling challenges and risks, the uncertain, the public security organs to maintain social harmony and stability of the task more difficult. Facing the new situation, new tasks and new requirements and new challenges, the traditional social security system has been difficult to adapt to the social security situation vary from minute to minute. And there is an urgent need to build new social security prevention and control system which bases on the information age.

\section{Social security prevention and control system operation based on information}

Information-led social security prevention and control system includes information warning mechanism, emergent response mechanism, information supervisory control mechanism, information led investigation mechanism, and execution and supervision of law based on .net and assessment mechanism.

The first is sensitive information warning mechanism. Information warning mechanism is the first step and the important foundation of social security prevention and control system operation. The mechanism feedbacks social security timely and sensitively, and conveys a set of relevant information, which guides the whole control system operation effectively. All these are the basic premise of social security prevention and control system normal operation. The mechanism can raise the key social security prevention measures with the time and stage, which through the dynamic analysis about the area unstable factors, crime characteristics, places special industry, etc. The analysis above is based on the police integrated application information system and information resources on the Internet. Through the horizontal analysis on the adjacent regions and the similar social situation area, mechanism also can forecast security trends and development situation in the region. Upon the horizontal analysis above, the corresponding prevention and control measures can be settled to make the countermeasures more targeted, and effective.

The second is emergent response mechanism. Under the dynamic security environment, the police strive to arrest the suspects in the crime area and in the initial stage. The more sensitive the intelligence information is, the faster the reaction is made, the probability of capturing criminal 
suspects is larger, which makes the public security work cost lower. The emergent response mechanism takes the police information integrated application system as the support, and takes the command center for the hub. The mechanism can highly integrate the geographic information and Street police information, such as various anti-riot card points, security checkpoints, taxi security management service station, security watch box in a real time. When a crime case occurs, the nearest police disposal can be scheduled at once, the first-line receiving police information can be collected for decision making. The emergent response mechanism tracks the implementation commands and all information about the crime cases, which enhances the police power cooperative effectiveness. The mechanism helps police form an instant, convenient and efficient dealing with alarm pattern, which makes the information network become the central nervous of public security organs at all levels in rapid response mechanism.

The third is information supervisory control mechanism. The information supervisory control mechanism is a mixed information monitoring system, which is based on the relationship with various kinds of information system such as transient population, the hotel industry, private rental accommodation, Internet cafes, vehicle management, consignment, pawn repair industry waste materials purchasing industry, second-hand mobile phone market etc. The mechanism can realize automatic relevance, automatic alignment, and automatic alarm, and also can take the online real time and full process control over the suspects and stolen goods. The internet suspected criminal, suspicious items feedback information should be checked seriously. And according to the information of suspected criminal object types, crime means, and the criminal suspect degree, the supervisory control can be divided into different objects and hierarchy. Then the investigation and control responsibilities can relate to the relevant departments, the police do a good job tracking and control. Once finds the evidence of the crime in the mechanism, the investigation starts rapidly, and the crime suspects will be grasped in real time.

The fourth is information-led investigation mechanism. In a certain sense, the criminal investigation work is a professional process of backtracking, expose, prove of the criminal behavior, which is based on the acquisition of crime in the process of implementation of personnel, goods, tools and other information. Information has always been a lifeline position in the investigation, and all the investigation activities and measures are based on achieving crime related information extremely. Therefore, the new concept of information led investigative work should be firmly established. Then initiative attacking operation model which takes human, card, line, places and other information as a starting point, should vigorously promote. The information application is highly valued overall the whole process during the investigation process, which the information investigation fugitives throughout the beginning, further exploration, summary, rich, the activation information investigation tactics, tactics, improve the comprehensive application of the general police accurate retrieval, fuzzy query, cross matching, tracking retrieval, human-computer combination analysis etc. tactics ability rolling, improve the working accuracy and efficiency overall the whole process of application information.

The fifth is powerful execution and supervision of law based on .net and assessment mechanism. Such supervision and evaluation, assessment work should advance with the times, adapt to the information requirements. To make full use of the information flow of the system and the standardization advantages, the online examination, examination and approval work should be actively promoted, which can realize all network operation and monitoring of the examination, approval and issuance of legal instruments during all aspects of the review, starting from The criminal, administrative case to the case processing. In addition, the case based on voice telephone query system is to implement the general, which is ready to accept the query and supervision by the masses. Then placing cases on unreal file, and denial of justice will be further solved. If there is some conditional of primary science team, a computer touch screen query table can be built, which the enforcement, administrative examination and approval of the basis, process and results are open to the whole society. The construction of the computer touch screen query table can improve management and service efficiency. In this way, the information system should be made full use, which will realize the dynamic tracking supervision and law enforcement aspects of the 
implementation of the entire process, the full range, to ensure the quality and efficiency of law enforcement. Finally, supervision of law based on .net should be vigorously promoted, in which the implementation of online score assessment through the information system of quantitative standard, so that unified examination work can follow the principle of authority, openness, impartiality and fairness.

\section{The problems should be paid Attention in the system operation}

First is steadfast the leading concept. Information must fully play a leading role in information-led social security prevention and control system. Social security prevention and control system is to ensure efficient operation, the police must ensure its leading role: (1) Information must be collected fully by social security prevention and control system, and through these all-round and multi-channel information, the state and trend of social development can be grasped comprehensive and accurately. (2) After information collection, information should be timely analysis, so that the police can accurately grasp the characteristics of criminal prevention. Then the information analysis can provide timely guidance to control power and dosage, and also improve the forward-looking and proactive prevention and control work. (3) Early warning information should be published timely, which can positive interaction directing the prevention and control of resources. All these can improve the risk of crime rate and the capture rate. (4) The work flow must clear and practical, every link in information collection, analysis, use, feedback and other links etc. should be clear responsibility, mutual connection, and measures are in place.

Second is the operational mechanism improvement, and strengthen mechanisms to ensure the social security prevention and control system. In the information process, the technology application limitation of police traditional working mechanism is to break out. And also the mechanism innovation should be taking as the focus of security information intelligence led policing strategy, and science technology mechanism guarantees the technical feedback. In the management aspects, first is to determine top leader leadership mechanism, and ensure the police leader of public security organs as directly responsible people for the information construction and other leaders are responsible for the division of police system. Second is to establish a set of management system, specialized information management department should be established in the city, the county public security organs. In this management system, a top-down management organization is clear, in which the basic public security is to build part-time information staff groups, and the management team in public security organs. In application aspects, work specification is used to clear job responsibilities, and form the whole police application mechanism. Through the technology system, police coordination, resource sharing, mutual support, results altogether can be realized between the different kinds of police. In system security aspect, establish expenditure security system and personnel incentive mechanism through the planning and management of talents. Further more the annual expenditure for public security guarantee must ensure a certain proportion for information construction, and pay more attention for technical personnel policies to promote and reward. And all above will provide sustainable development safeguard for information construction. In the police operation aspect, adhere to promote reforms with application of information technology, innovation the police command system for the content of "three systems in one", in which mechanism, information command system takes information platform as the carrier, the police based management mechanism takes population as core, the police case management mechanism takes the information system workflow as control means, population management system takes internet as the base. Otherwise, the level of social security prevention and control system is very strong, which contains many subsystems. And then each subsystem can be divided into smaller subsystems or elements, such as the prevention of civil air defense, physical defense, technology etc..

Third is increasing the information network construction investment, which provides technical support for the construction of social security prevention and control system. Along with the social security system application projects, the number of concurrent users will increase rapidly, and the response speed of the system can significantly reduce, the network may quickly appear bottleneck, 
so the network capacity expansion is very urgent. In order to improve the problem above, the hardware investment should be further increase, which can strengthen the network basic support function. After the a more efficient network constructs, through the use of information communication network access and wireless mobile police information system, information-led social security prevention and control system can vigorously to the Criminal Police Brigade, Traffic and patrol police squadron, community police room, security card point, vehicle management, public security detention, reeducation, compulsory detoxification institute, and other public operational departments and front-line police extension. For this, construction of horizontal and vertical network can support to the social security system.

\section{Acknowledgements}

This work was financially supported by A Project Funded by the Priority Academic Program Development of Jiangsu Higher Education Institutions, the University Philosophy and Social Sciences Research Project of Jiangsu Province (No.2014SJD194) and the Research Project of Jiangsu Police Institute: Research on the city emergency management system based on GIS(No.13Q18).

\section{Reference}

[1]K.Q. Wu. Foreign Research on Information Leading Policing [J]. Public Security. 2005, (7):88.

[2]H. Yu. Try Discussing Elements in Police Enforcement with Science and Technology [J]. GuangDong Province Public Security Technology. 2006, (2).

[3]H.Z. Wang. Using Information-led Police Affairs to Promote Policing Pattern of Strike, Prevention and Control [J]. Journal of Zhejiang Police College. 2005, (4): 6-7.

[4]Q. Chen. Social Security Prevention and Control System Construction must Pay Attention to the Information Guided Policing Strategy [J]. Journal of Shanghai Police Academy. 2005, (5):44.

[5]H.Z. Wang. Using Strike, Prevention and Control Police Application to Promote the Construction of Police Information Technology [J]. The Public Security Research. 2003,(12):42.

[6]D. Cai, C. Gao. Design of Urban Emergency System Based on 3S Spatial Information Technology [J]. Applied Mechanics and Materials. 2014, 6707-6710. 